\title{
sciendo
}

CIVIL AND ENVIRONMENTAL ENGINEERING REPORTS

E-ISSN 2450-8594

CEER 2019; 29 (2): 041-049

DOI: 10.2478/ceer-2019-0015

Original Research Article

\section{VISCOELASTIC MATERIAL AS ENERGY DISSIPATER VISCOELASTIC DAMPER FOR BUILDING STRUCTURES TO MITIGATE THE SEISMIC VIBRATION}

\author{
Waseem SARWAR ${ }^{1}$ \\ Department of Civil Engineering, Southeast University, Nanjing, China
}

\begin{abstract}
The supplemental energy dissipation system is a practical approach to attenuate the structural response under extreme loading. Viscoelastic damping used to reinforce the structure against the seismic vibration, Viscoelastic material (VEM) most commonly used in viscoelastic dampers (VEDs). In this paper, dynamic mechanical analysis (DMA) approach is used to investigate the performance index of VEM. It is demonstrated that the performance index, such as storage modulus, loss modulus, and loss factor decrease noticeably as the temperature increases, which reflects the low stiffness at high temperature. Excitation frequency also influenced the performance index, and the reaction has correspondence to temperature. As the temperature increases, the VEM dynamic properties decreases, which represents the rubbery region, and it is found that higher to low-temperature dynamic properties increases, which the glassy region is. DMA is a particularly flexible approach, and it characterizes the properties of VEM simultaneously at various conditions.
\end{abstract}

Keywords: Viscoelastic material, Viscoelastic dampers, Dynamic mechanical analysis, Dynamic properties, seismic control

\footnotetext{
${ }^{1}$ Corresponding author: Department of Civil Engineering, Southeast University, Nanjing, China, e-mail: waseem_seu@outlook.com
} 


\section{INTRODUCTION}

Over the past few decades, the vibration control approach has taken a significant appearance in the seismic design of building structures; this approach is more cost effective and safer design can be attained by adding supplemental damping devices to reduce the damages. In order to attenuate the structural response during the severe seismic activity, viscoelastic damping material is most commonly used in viscoelastic dampers (VEDs) to mitigate the seismic vibration in engineering structures [1-3]. The dynamic performance index of VEM are rather complex and depend on various factors such as temperature and frequency [4, 5]. Furthermore, the temperature rises within the viscoelastic material when subjected to shear deformation [6].

In this paper, the dependence of the performance index of the viscoelastic material on working frequency and temperature has been considered. In the dynamic mechanical analysis, VEM experience shear deformation, which is the most reliable approach to analyze the dynamic scope, and DMA test, correlates to the VEDs fatigue test when damper subjected to shear deformation. However, for the development of high energy dissipation VEDs; VEM properties are verified on a small scale, which is a reliable approach.

\section{BACKGROUND}

\subsection{Viscoelastic material (VEM)}

Energy dissipation properties of Viscoelastic materials (polymers) are highly sensitive to working frequency and the environmental temperature $[6,7]$. However, the dependency of material on these factors significantly influences the performance of viscoelastic material and their applications. Storage modulus $\mathrm{G}_{1}$ is the stiffness measure of the VEM and is equivalent to the energy stored when subjected to shear or axial loading. Loss modulus $\mathrm{G}_{2}$ is the measure of energy lost as heat during a cycle of deformation. Loss factor $\eta$ is the ratio of loss modulus to storage modulus and measure of actual damping provided by the viscoelastic system. Generally, VEM categorizes with the temperature sweep, and it can break into three different region/zone, glassy region, transition region, and rubbery region. At low-temperature dynamic properties are high, which represents the high stiffness of VEM in the glassy region. On the other hand, at high temperature lessen the dynamic properties which depict the rubbery region, and the physical state in between two regions is the transition region. 


\subsection{Viscoelastic dampers (VEDs)}

Typical VEDs consist of VE material pads bonded between the steel plates as can be seen in Fig. 1. VEDs are a type of passive control system which is designed to attenuate the structural response when subjected to seismic events, and dissipate the input energy in the form of heat when experiences shear deformation. Wide range of tests has now been performed on these VEDs in order to investigate the force-deformation behavior $[8,9]$ and their dynamic properties such as storage modulus, loss modulus, and loss factor. Fig. 2 depicts the typical Forcedeformation hysteresis loop of VED corresponds to equation 1 when subject to cyclic shear deformation. Moreover, the regular hysteresis loops represent the excellent energy dissipation capacity at a specific range of frequency and temperature. In force-deformation equation $1, \mathrm{~F}_{\mathrm{V}}$ is supplemental damping force; the $\mathrm{u}_{\mathrm{V}}$ is equivalent displacement; $\mathrm{k}_{\mathrm{V}}$ represents the equivalent stiffness of damper; $u_{0}$ is maximum displacement; $\eta$ is loss factor. In the given equations, $\mathrm{n}_{\mathrm{V}}$ represents the number of VEM layers, $A_{V}$ represents the total area of each VEM layer; $F_{1}$ is damping force at maximum displacement; $F_{2}$ is a force at zero displacements. VEDs Energy dissipation per cycle of shear deformation can be calculated by equation 5 .

$$
\begin{gathered}
\left(\frac{F_{V}-k_{V} u_{V}}{\eta k_{V} u_{0}}\right)^{2}+\left(\frac{u_{V}}{u_{0}}\right)^{2}=1 \\
G_{1}=\frac{F_{1} h_{V}}{n_{V} A_{V} u_{0}} \\
\eta=\frac{F_{2}}{F_{1}} \\
G_{2}=\eta G_{1} \\
E_{d}=\frac{\pi n_{V} A_{V} \eta u_{0}^{2} G_{1}}{h_{V}}
\end{gathered}
$$




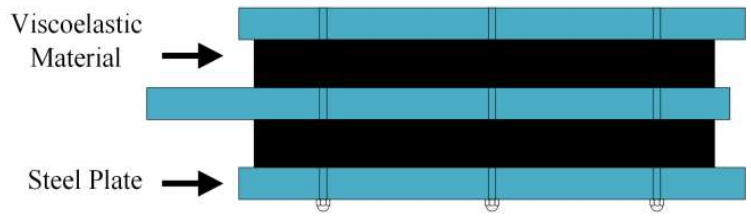

Fig. 1. Typical viscoelastic damper

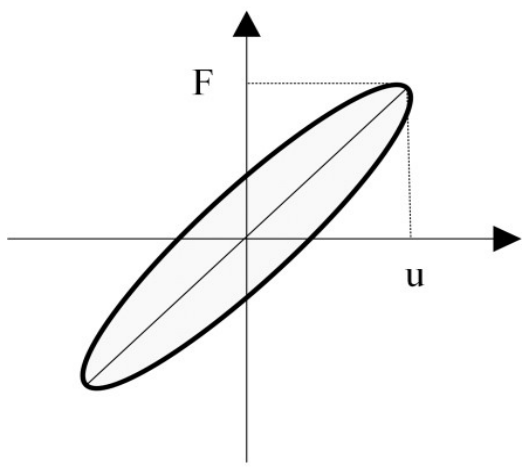

Fig. 2. Typical hysteresis loop of viscoelastic damper

\section{DMA TEST SETUP}

The dynamic mechanical analysis (DMA) test at $2 \%$ strain rate was carried out on the DMA (Q 800) apparatus under shear deformation as illustrated in Fig. 3. that export all dynamic properties; storage modulus, loss modulus, and loss factor in the output files, and during the DMA several test condition can be changed and controlled according to the test plan. The test is carried out under four different excitation frequencies $0.1 \mathrm{~Hz} ; 0.5 \mathrm{~Hz} ; 1.0 \mathrm{~Hz}$; and $2.0 \mathrm{~Hz}$ at $2 \%$ strain rate with working temperature sweep $10^{\circ} \mathrm{C} ; 20^{\circ} \mathrm{C} ; 30^{\circ} \mathrm{C}$ and $40^{\circ} \mathrm{C}$, parameters given in Table 1. VEM test sample was placed between the one flexible and two fixed clamps and was exposed to the imposed controlled stress or shear deformation, and then VEM dynamic properties were recorded.

Table 1. Test parameters

\begin{tabular}{ll}
\hline \multicolumn{2}{c}{ Dynamic mechanical analysis } \\
\hline Sample mounting & Shear mode \\
VEM sample dimensions & $10 \mathrm{~mm}^{2}, 4 \mathrm{~mm}(\mathrm{~T})$ \\
Frequency range $(\mathrm{Hz})$ & $0.1,0.5,1,2$ \\
Strain rate & $2.0 \%$ \\
Temperature range $\left({ }^{\circ} \mathbf{C}\right)$ & $10,20,30,40$ \\
\hline
\end{tabular}




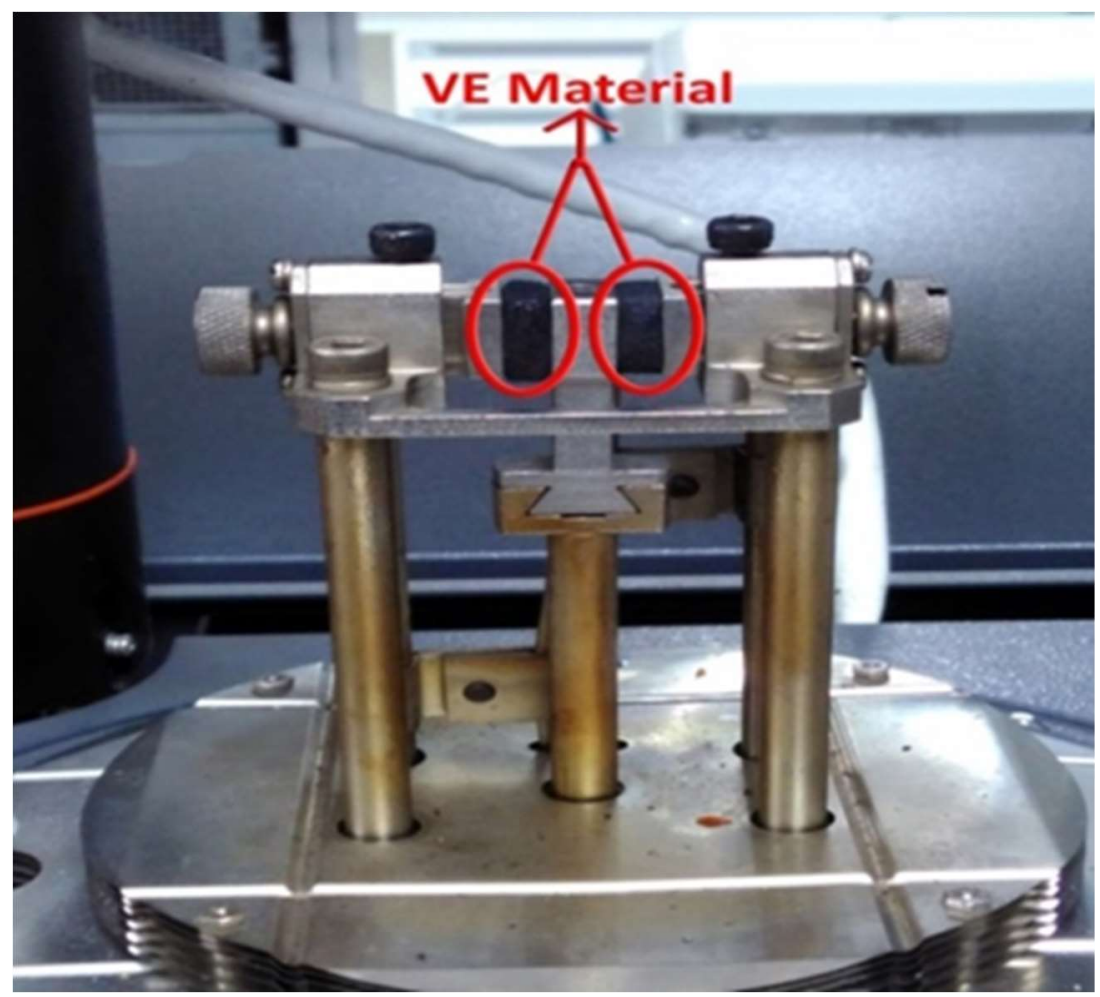

Fig. 3. Dynamic-mechanical analyzer and viscoelastic material under shear mode

\section{DMA RESULTS AND DISCUSSIONS}

\subsection{Temperature influence on dynamic properties}

VEM strongly influenced by the temperature as illustrated in Fig. 4. storage modulus decreases as the temperature increase, the difference in storage modulus at $10^{\circ} \mathrm{C}$ to $20^{\circ} \mathrm{C}$ with constant frequency $2.0 \mathrm{~Hz}$ is $26.24 \%$, It represents the decrease in stiffness and rubbery behavior. Fig. 5 shows the variation in loss modulus with the increase in temperature as discussed in the above section; loss modulus is the measure of energy lost, however, decrease in loss modulus represents the decrease in energy dissipation, and the difference in loss modulus at $10^{\circ} \mathrm{C}$ to $20^{\circ} \mathrm{C}$ with constant frequency $2.0 \mathrm{~Hz}$ is $75.66 \%$. As illustrated in Fig. 6 . decrease in loss factor with the increase in temperature which is actual mechanical damping of VEM, this behavior represents elastic properties, and the difference in loss factor at $10^{\circ} \mathrm{C}$ to $20^{\circ} \mathrm{C}$ with constant frequency $2.0 \mathrm{~Hz}$ is $51.99 \%$. 


\subsection{Frequency influence on dynamic properties}

Excitation frequency influenced the dynamic behavior of VEM, as illustrated in Fig. 4-6. Storage modulus increases with the increase in frequency, the difference in storage modulus at $2.0 \mathrm{~Hz}$ to $1.0 \mathrm{~Hz}$ with constant temperature $10^{\circ} \mathrm{C}$ is $11.51 \%$. Loss modulus increases with the increase in frequency, the difference in loss modulus at $2.0 \mathrm{~Hz}$ to $1.0 \mathrm{~Hz}$ with constant temperature $10^{\circ} \mathrm{C}$ is $34.28 \%$. Loss factor increases with the increase in frequency, the difference in loss factor at $2.0 \mathrm{~Hz}$ to $1.0 \mathrm{~Hz}$ with constant temperature $10^{\circ} \mathrm{C}$ is $22.99 \%$.

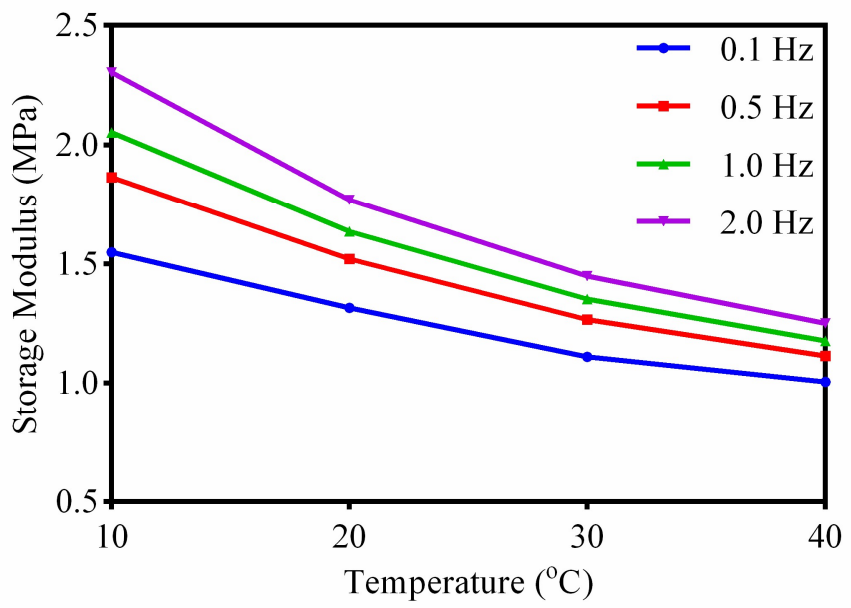

Fig. 4. Change in storage modulus at a different frequency $(\mathrm{Hz})$

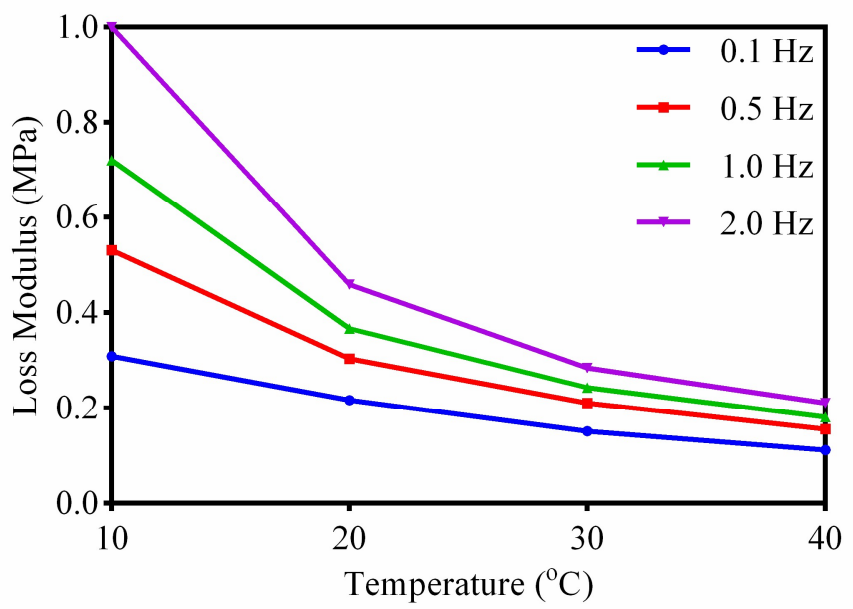

Fig. 5. Change in Loss modulus at a different frequency $(\mathrm{Hz})$ 


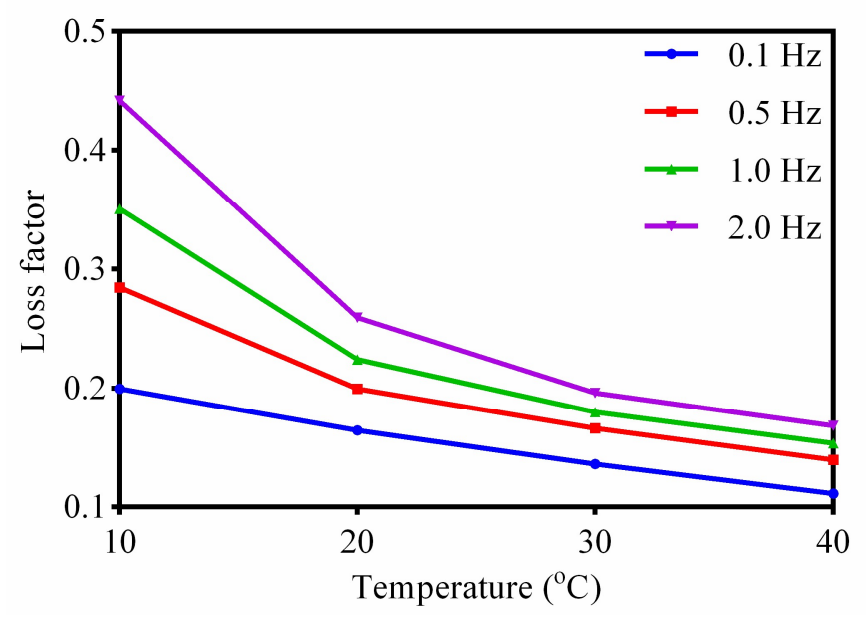

Fig. 6. Change in Storage modulus at a different frequency $(\mathrm{Hz})$

\subsection{Discussions}

Storage and loss moduli are strongly influenced by the disturbance frequency, at low-frequency VEM response was elastic as illustrated in the above figures, and at high-frequency response was stiffer. This philosophy discloses material structure that at low frequency, the VEM chains can achieve equilibrium state while at high frequency; the VEM structure chains cannot approach the equilibrium state results in dissipating the energy. Furthermore, at lowtemperature dynamic response is maximum, which represents the rigidity, as the temperature increases, rigidity and stiffness decrease. Mostly viscoelastic supplemental damping analyzed as loss factor that is energy lost measure per cycle of shear displacement or strain. It is valuable to analyze the dynamic properties at wide range of excitation frequency and temperature because these parameters significantly depending on the seismic vibration. Dynamic scope of VEM revealed by using DMA for the development of VEDs, although many researchers performed VEDs fatigue tests $[10,11]$, but less attention has been paid on small scale test of VEM which is more accurate than VEDs fatigue test approach. The DMA test results were analyzed to classify the dynamic scope of VEM and then proceed to develop the high energy dissipation capacity VEDs for building structures to attenuate the seismic vibration.

\section{CONCLUSIONS}

DMA is a hypersensitive approach for investigating the dynamic scope of VEM. It facilitates in the characterization of polymers and gives enough information 
about VEM, which is essential for the development of supplemental damping systems such as VEDs, other mechanical products, and industrial applications. Dynamic properties of VE material are investigated, the DMA (Q 800) apparatus reported fair differences in properties at various frequencies and temperatures. Storage modulus, loss modulus, and loss factor increases with the increase in excitation frequency and decrease as the temperature increases. However, the variation in properties with working conditions should be considered during the development of VEDs and their application in engineering industries.

FUNDING: This research received no external funding.

CONFLICTS OF INTEREST: The author declares no conflict of interest.

\section{REFERENCES}

1. Ghaemmaghami, AR and Kwon, OS 2018. Nonlinear modeling of MDOF structures equipped with viscoelastic dampers with strain, temperature and frequency-dependent properties. Engineering Structures 168, 903-914.

2. Lee, KS, Fan, C-P, Sause, R and Ricles, J 2005. Simplified design procedure for frame buildings with viscoelastic or elastomeric structural dampers. Earthquake Engineering \& Structural Dynamics 34, 1271-1284.

3. Mazza, F and Vulcano, A 2011. Control of the earthquake and wind dynamic response of steel-framed buildings by using additional braces and/or viscoelastic dampers. Earthquake Engineering \& Structural Dynamics 40, 155-174.

4. Kawak, BJ, Cabon, BH and Aglietti, GS 2017. Innovative viscoelastic material selection strategy based on dma and mini-shaker tests for spacecraft applications. Acta Astronautica 131, 18-27.

5. Martinez-Agirre, M, Illescas, S and Elejabarrieta, MJ 2014. Characterisation and modelling of prestrained viscoelastic films. International Journal of Adhesion and Adhesives 50, 183-190.

6. De Lima, AMG, Rade, DA, Lacerda, HB and Araújo, CA 2015. An investigation of the self-heating phenomenon in viscoelastic materials subjected to cyclic loadings accounting for prestress. Mechanical Systems and Signal Processing 58-59, 115-127.

7. Borg, T and Pääkkönen, EJ 2010. Linear viscoelastic models: Part IV. From molecular dynamics to temperature and viscoelastic relations using control theory. Journal of Non-Newtonian Fluid Mechanics 165, 24-31. 
8. Chang, KC, Soong, TT, Oh, S-T and Lai, ML 1995. Seismic Behavior of Steel Frame with Added Viscoelastic Dampers. Journal of Structural Engineering 121, 1418-1426.

9. Bergman, DM and Hanson, RD 1993. Viscoelastic Mechanical Damping Devices Tested at Real Earthquake Displacements. Earthquake Spectra 9, 389-417.

10.Mehrabi, MH, Suhatril, M, Ibrahim, Z, Ghodsi, SS and Khatibi, H 2017. Modeling of a viscoelastic damper and its application in structural control. PLOS ONE 12, e0176480.

11.Tsai, CS and Lee, HH 1993. Applications of Viscoelastic Dampers to High Rise Buildings. Journal of Structural Engineering 119, 1222-1233.

Editor received the manuscript 1.06.2019 